\title{
Supramolecular Structuring of Hyaluronan-Lactose-Modified Chitosan Matrix: Towards High-Performance Biopolymers with Excellent Biodegradation
}

\author{
Riccardo Ladiè ${ }^{1}$, Cesare Cosentino ${ }^{1}$, Irene Tagliaro ${ }^{2}{ }^{\mathbb{D}}$, Carlo Antonini ${ }^{2} \mathbb{D}$, Giulio Bianchini ${ }^{3}$ \\ and Sabrina Bertini ${ }^{1, *}$ (D) \\ 1 Istituto di Ricerche Chimiche e Biochimiche G. Ronzoni, Carbohydrate Science Department, \\ 20133 Milan, Italy; ladie@ronzoni.it (R.L.); cosentino@ronzoni.it (C.C.) \\ 2 Department of Materials Science, University of Milano-Bicocca, 20125 Milan, Italy; \\ i.tagliaro@campus.unimib.it (I.T.); carlo.antonini@unimib.it (C.A.) \\ 3 JoinTherapeutics Srl, 35122 Padova, Italy; giulio.bianchini@jointherapeutics.com \\ * Correspondence: bertini@ronzoni.it; Tel.: +39-02-70641627
}

\section{check for} updates

Citation: Ladiè, R.; Cosentino, C.; Tagliaro, I.; Antonini, C.; Bianchini, G.; Bertini, S. Supramolecular Structuring of

Hyaluronan-Lactose-Modified Chitosan Matrix: Towards High-Performance Biopolymers with Excellent Biodegradation. Biomolecules 2021, 11, 389. https:// doi.org/10.3390/biom11030389

Academic Editor: Dragana Nikitovic

Received: 28 January 2021

Accepted: 26 February 2021

Published: 5 March 2021

Publisher's Note: MDPI stays neutral with regard to jurisdictional claims in published maps and institutional affiliations.

Copyright: (c) 2021 by the authors. Licensee MDPI, Basel, Switzerland. This article is an open access article distributed under the terms and conditions of the Creative Commons Attribution (CC BY) license (https:/ / creativecommons.org/licenses/by/ $4.0 /)$.

\begin{abstract}
Non-covalent interactions in supramolecular chemistry provide useful systems to understand biological processes, and self-assembly systems are suitable assets to build-up innovative products for biomedical applications. In this field, polyelectrolyte complexes are interesting, especially when polysaccharides are involved, due to their non-toxicity and bio-absorbability. In this work, we investigated a polyelectrolyte formed by hyaluronic acid (HA), a negatively charged linear polysaccharide, with Chitlac (Ch), a positively charged lactose-modified chitosan. The aim of the study was the investigation of a novel Ch-HA polyelectrolyte complex, to understand the interaction between the two polysaccharides and the stability towards enzymatic activity. By means of gel permeation chromatography-triple detector array (GPC-TDA), nuclear magnetic resonance (NMR), dynamic viscosity, Zeta Potential and scanning electron microscopy (SEM), the polyelectrolyte complex properties were identified and compared to individual polysaccharides. The complex showed monodisperse molecular weight distribution, high viscosity, negative charge, and could be degraded by specific enzymes, such as hyaluronidase and lysozyme. The results suggest a close interaction between the two polysaccharides in the complex, which could be considered a self-assembly system.
\end{abstract}

Keywords: chitosan; hyaluronic acid; lactose modified chitosan; NMR; molecular weight distribution; SEM; rheology; hyaluronidase

\section{Introduction}

Supramolecular chemistry relies on non-covalent interactions, like hydrogen bonds, hydrophobic and Van der Waals forces, and metal-ligand coordination. These interactions control many self-assembly processes, such as biological processes, and can be used to design innovative products for biomedical applications. Polysaccharides, due to their promising biomedical and biological applications, such as tissue engineering, biosensor and wound healing, are a particularly interesting class of molecules: intra- and inter-chain interactions, together with ion pairs, originate primary, secondary, tertiary, and quaternary structures, leading to supramolecular architectures [1,2]. Such architectures are suitable for a variety of applications, ranging from drug delivery to enhance the bioavailability of poorly soluble drugs [3]. Hydrophobized polysaccharides were synthetized to produce supramolecular structures in water, and their interactions with soluble proteins or other molecular assemblies, such as monolayers, black lipid membranes, liposomes and oil-inwater emulsion were studied [4].

Among the extensive number of polysaccharides available as candidates for biopolymer engineering, glycosaminoglycans (GAGs) are highly promising candidates [5]. GAGs 
are linear polysaccharides, which consist of repeating disaccharide units, usually include a uronic acid component (such as glucuronic acid), and a hexosamine component (such as $\mathrm{N}$-acetyl-D-glucosamine).

In particular, hyaluronic acid (HA) is a linear polysaccharide with a poly-repeating disaccharide structure $[(1 \rightarrow 3)-\beta-D-G l c N A c-(1 \rightarrow 4)-\beta-D-G l c A]$, which can be found ubiquitously in all vertebrate tissues extracellular matrix (ECM) [6,7]. Glucuronic acid residues contain a carboxyl group, which confers a negative charge on HA. Despite its relatively simple chemical composition, HA is involved in several biological functions, such as morphogenesis, tissue remodelling, inflammation, and tumours development and metastasis; in addition, HA contributes directly to the maintenance of tissue homeostasis and biomechanics [7]. Biocompatibility, biodegradability, high viscoelasticity, and immunoneutrality make HA an attractive polymer for biomedical and pharmaceutical applications. Frequently, HA acts as a space filler, applied to treat joint diseases such as in osteoarthritis and in eye surgery as replacement fluid, for drug delivery, and tissue engineering applications. HA is availed in viscosupplementation therapy, with the therapeutic goal to restore the viscoelasticity of synovial fluid. Indeed, HA is continuously secreted in the articular cavity and is one of the most common components of synovial liquid, giving rise to its characteristic viscoelastic properties. These rheological properties are essential for the lubrication and shock protection of healthy joints, allowing the protection of cartilage and soft tissues. In the event of traumatic and degenerative diseases, the amount of HA is lowered and synovial fluid experiences a viscosity drop, impairing joint functionality, and causing pain [8-10]. For applications, unmodified HA and chemically modified or cross-linked HA are used [11,12]; the derivatization of HA increases its mechanical properties and stability, which allows it to be used as a biomaterial [13-15].

Chitosan is also a linear polysaccharide, derived from deacetylation of chitin, the structural component of fungal cell walls, and exoskeleton of arthropods. It is composed of $\beta-1 \rightarrow 4$ glucosamine units, with some residual interspersed $\mathrm{N}$-acetyl-glucosamine residues; it is soluble in acidic solution, with a positive charge density, dependent on $\mathrm{pH}$ and percentage of deacetylation. Chitosan is well-known for its numerous and interesting biological properties - it is biocompatible, bioresorbable, and bioactive. Availability, safety for medical use, and biodegradability make chitosan very interesting for tissue engineering and biomaterials products. Chitosan can be further improved from the bioactive features and the physical-chemical behaviour. In particular, Chitlac $(\mathrm{Ch})$ is a compound obtained by the modification of chitosan with lactitol moieties [16], in which the oligosaccharide pendant groups alter its solubility at physiological $\mathrm{pH}$. The physico-chemical and biological properties of $\mathrm{Ch}$ are already reported in the literature [17].

Both HA and $\mathrm{Ch}$ are hydrolyzed by enzymes; linear HA can be easily degraded by enzymes, such as bovine testicular hyaluronidase, an endo- $\beta-\mathrm{N}$-D-acetylhexosaminidase that hydrolyzes HA at the $\beta(1 \rightarrow 4)-\mathrm{N}$-acetylglucosaminide bonds [18]. Hyaluronidases simultaneously display both hydrolytic and transglycosylation activities-the optimal conditions for the hydrolysis of $\mathrm{HA}$ by hyaluronidase are $\mathrm{pH} 4.0$ and the presence of $\mathrm{NaCl}$, whereas for transglycosylation they are $\mathrm{pH} 7.0$ and the absence of $\mathrm{NaCl}$ [19]. In the case of $\mathrm{Ch}$, there is no specific enzyme; nonetheless, previous studies report that degradation can be performed by lysozyme, which is, for example, present at concentrations ranging from 4 to $13 \mathrm{mg} / \mathrm{L}$ in serum and in tears (450 to $1230 \mathrm{mg} / \mathrm{L}$ ) [20].

A polyelectrolyte complex is formed when polymers with opposite charges are combined in solution. A strong complex is obtained if the anions and cations in the polymers contain strong acids and bases, or if the polyions attain their fully ionized forms and vice versa. The polyelectrolyte complexes are recently gaining attention as supramolecular carriers for controlled release of drugs and proteins [21], which is widely used in many applications such as membranes, medical prosthetics, environmental sensors, and protein separation systems [22,23]. These complexes prepared from natural polymers, such as polysaccharides, have the additional advantage of being non-toxic and bioabsorbable [24]. For example, biomaterials, constituted of a Chondroitin sulphate-Chitosan complex, have 
interesting biological properties, such as wound-healing acceleration and cellular assistance for skin and cartilage recovery [25]. Some applications of Chitosan and HA complexes include ophthalmic surgery, arthritis treatment, scaffolds for wound healing, tissue engineering, and the use as a component in implant materials. In particular, different authors showed that the potential of Chitosan/HA complexes coacervates in the biomaterials field [26-31]. A recent study about self-supporting multi-layered film containing a Chitosan and HA polyelectrolyte complex, showed high selectivity during the separation of water from the ethanol-water mixtures for membrane technology applications [32].

Moreover, recent studies highlighted promising results for biological and medical applications of the HA/Ch complex, such as in the treatment of osteoarthritis $[33,34]$; in vivo osteoarthritis treatments with a viscosupplementation containing $\mathrm{Ch}$ and HA showed a decrease in morphological and histolopathological cartilage damage and synovial membrane inflammation, in comparison to the treatment performed with HA alone [33]. A combination of $\mathrm{Ch}$ and HA-attenuated macrophage-induced inflammation, inhibited metalloproteinases expression, and exhibited anti-oxidative effects, providing interesting insights into the biological effects of mixture of these polysaccharides for the development of osteoarthritis treatments [34]. However, the literature does not provide exhaustive chemical-physical characterization of $\mathrm{HA} / \mathrm{Ch}$ for a better understanding of the observed biological performances.

As such, in this work we investigated the properties of the polyelectrolyte complex to understand the interaction between HA and Ch. Specifically, the molecular weight of the supramolecular product through size-exclusion chromatography with a triple detector array (HP-SEC-TDA) was determined. The viscosity property and the molecular mobility was elucidated through dynamic viscosity and NMR diffusion ordered spectroscopy (DOSY) experiments, respectively. Finally, the stability toward enzymatic actions was evaluated.

\section{Materials and Methods}

\subsection{Materials}

Ch was provided by Join Therapeutics S.r.l. (Padova, Italy). Sodium Hyaluronate were purchased from HTL Biotechnology. Sodium azide, sodium nitrate, sodium dihydrogen phosphate monohydrate, sodium hydrogen phosphate dihydrate, trimethylsilyl-3propionic acid (TSP), Hyaluronidase from bovine testes (400-1000 u/mg) and Lysozyme from hen egg white $(93,300 \mathrm{u} / \mathrm{mg}$ ) were purchased from SigmaAldrich (Milan, Italy). Deionized water (conductivity less than $0.1 \mu \mathrm{S}$ ) was prepared with an inverse osmosis system (Culligan, Milan, Italy). PolyCAL TM Pullulan std-57k (Malvern Instruments LtD, Malvern, United Kingdom). The reagent grades were $\geq 98 \%$.

\subsection{Molecular Weight Distribution by HP-SEC-TDA}

HP-SEC-TDA was used extensively to obtain molecular weight distribution of HA, $\mathrm{Ch}$, and the complex. This method does not require any chromatographic calibration and is considered to be suitable to analyze polysaccharides. Measurements for molecular weight distribution were performed on a Viscotek 305 HPLC system (Malvern Instruments LtD, Malvern, UK). The array exploits simultaneous action of refraction index detector (RI), viscometer, and Right Angle Laser Light-scattering (RALS) detector, using a method adapted from Bertini et al. [35]. To prepare the solutions for HP-SEC-TDA measurements, 10-20 mg was dissolved in a mobile phase volume, to obtain a sample concentration of $\sim 3 \mathrm{mg} / \mathrm{mL}$. The $\mathrm{Ch}$ solution was stirred for $3 \mathrm{~h}$ and then diluted in a mobile phase to a concentration of $\sim 1 \mathrm{mg} / \mathrm{mL}$. The HA solution was stirred overnight and then diluted in the mobile phase to a concentration of $\sim 0.5 \mathrm{mg} / \mathrm{mL}$, respectively. For the HA/Ch complex, $75 \mathrm{mg}$ of $\mathrm{Ch}$ were dissolved in $10 \mathrm{~mL}$ of phosphate-buffer saline solution $\mathrm{pH}$ 6.9 (PBS), and stirred at room temperature to obtain a completely solubilized solution. Afterwards, $125 \mathrm{mg}$ of HA were added to the solution and the complex was stirred for $12 \mathrm{~h}$. Prior to the analysis of the solution, the HA/Ch complex was diluted in a mobile phase to reach $1 \mathrm{mg} / \mathrm{mL}$ sample concentration. The analyses were performed at $40{ }^{\circ} \mathrm{C}$, 
using 2 x TSKPWXL columns in series (Tosoh Bioscience, $7 \mathrm{~mm} 7.8 \times 30 \mathrm{~cm}$ ). A total of $0.1 \mathrm{M} \mathrm{NaNO}_{3}$ for $\mathrm{HA}, 0.2 \mathrm{M} \mathrm{NaNO}_{3}$ for $\mathrm{Ch}$, and an $\mathrm{HA} / \mathrm{Ch}$ complex, both containing $0.05 \% \mathrm{NaN}_{3}$, prefiltered using $0.22 \mathrm{~mm}$ filter, were used at a flow rate of $0.6 \mathrm{~mL} / \mathrm{min}$. Chromatographic profiles were elaborated using the OmniSEC software version 4.6.2. RI increments, referred to as $d n / d c$, were determined to enable conversion of RI values into a concentration for $\mathrm{Ch}$ and HA/Ch [36]. $d n / d c$ values equal to $0.129 \mathrm{~mL} / \mathrm{g}$ and $0.119 \mathrm{~mL} / \mathrm{g}$ were observed for $\mathrm{Ch}$ and $\mathrm{HA} / \mathrm{Ch}$, respectively. For $\mathrm{HA}$, the $d n / d c$ value of 0.155 was taken from the literature [37].

\subsection{NMR Analysis}

The $\mathrm{Ch}$ and HA spectra were obtained with a Bruker AVANCE IIIHD $500 \mathrm{MHz}$ spectrometer (Bruker, Karlsruhe, Germany) equipped with a $5 \mathrm{~mm}$ BBO probe, at $343 \mathrm{~K}$. Spectra were processed with BrukerTopspin software version 4.0.6.

About $30 \mathrm{mg}$ of sample were dissolved in $3 \mathrm{~mL}$ of deuterium oxide (D2O) with $0.002 \%$ TSP and subsequently $0.6 \mathrm{~mL}$ were transferred into a $5 \mathrm{~mm}$ NMR tube. The HA sample was stirred overnight to ensure a complete solubilization before transfer in an NMR tube (Bruker, Karlsruhe, Germany) for the analysis. ${ }^{1} \mathrm{H}$ NMR spectra were acquired with pre-saturation of residual HDO, using 64 scans, 12 s relaxation delay, and a number of time-domain points equal to $32 \mathrm{k}$. For the Ch sample, the ${ }^{1} \mathrm{H}-{ }^{13} \mathrm{C}$ HSQC spectra were acquired using 16 scans, 5 s relaxation delay, ${ }^{1} \mathrm{~J}_{\mathrm{C}-\mathrm{H}} 150 \mathrm{~Hz}$.

The HA/Ch complex spectra were acquired with a Bruker AVANCE NEO 500MHz spectrometer (Bruker, Karlsruhe, Germany) equipped with a $5 \mathrm{~mm}$ TCI cryogenic probe at 303K for ${ }^{1} \mathrm{H}$ NMR and Diffusion Order NMR Spectroscopy (DOSY). Spectra were processed with Bruker Topspin software version 4.0.6. Ch and HA were dissolved separately in a PBS deuterium volume $(\mathrm{mL})$, which allowed us to reach $7.5 \mathrm{mg} / \mathrm{mL}$ and $12.5 \mathrm{mg} / \mathrm{mL}$, respectively. Then, $500 \mu \mathrm{L}$ of both solutions were taken and mixed, it was vortexed to obtain a homogeneous solution.

Spectra were acquired with pre-saturation of residual HOD using 64 scans, 5 s relaxation delay, and a number of time-domain points equal to $65 \mathrm{k}$.

DOSY experiments were acquired using the 2D-stimulated echo sequence with bipolar gradient pulse for diffusion. The gradient pulse $(\delta)$ and the diffusion time $(\Delta)$ were set to $5 \mathrm{~ms}$ and $300 \mathrm{~ms}$, respectively. The 2D DOSY experiments were run with gradients varied linearly from 5 to $95 \%$ in 32 steps, with 16 scans per step. The diffusion coefficients D were extracted using the Bruker Dynamics Center 2.5 (Bruker, Karlsruhe, Germany).

\subsection{Zeta Potential Analysis}

Zeta Potential (Zp) of HA, Ch, and the HA/Ch complex were measured using the Zetasizer Nano ZS (Malvern, Worcestershire, United Kingdom), with a fixed scattering angle of $173^{\circ}$ and a 633-nm helium-neon laser. Data were analyzed using the Zetasizer software version 7.11 (Malvern Instruments LtD, Malvern, UK). For the analysis, Ch and HA solutions were diluted in PBS to reach the concentration of 7.5 and $12.5 \mathrm{mg} / \mathrm{mL}$, respectively. In the case of the $\mathrm{HA} / \mathrm{Ch}$ complex, $75 \mathrm{mg}$ of $\mathrm{Ch}$ were dissolved in $10 \mathrm{~mL}$ of PBS and stirred at room temperature, to obtain a completely solubilized solution. Then, about $125 \mathrm{mg}$ of HA were added to the solution and the complex was stirred for $12 \mathrm{~h}$. Disposable plastic cuvettes DTS1070 were used for the Zp analysis.

\subsection{Rheological Properties}

The rheological properties of HA, Ch, and the complex were studied using a Modular Compact Rheometer MCR 92 (Anton Paar GmbH, Graz, Austria), equipped with a 50-mmdiameter cone-plate geometry, with a cone angle of $1^{\circ}$. For all tests, the temperature and the gap between the plates were kept constant $20^{\circ} \mathrm{C}$ and $0.98 \mathrm{~mm}$, respectively.

Viscosity measurements were performed in rotation mode, they were investigated in the range of $0.1-100 \mathrm{~s}^{-1}$ and ten points per decade were acquired. 
The sample viscoelastic behaviour was investigated in the oscillation mode, to determine the storage modulus $G^{\prime}(\omega)$ and the loss modulus $G^{\prime \prime}(\omega)$. First, preliminary tests were conducted to determine the upper amplitude limit of the linear viscoelastic region (LVE), testing the samples over an extended strain field (0.01-100\%). Second, after the LVE was determined ( $2 \%$ for $\mathrm{HA}$ and $\mathrm{HA} / \mathrm{Ch}$ and $20 \%$ for $\mathrm{Ch}$ ), the samples were tested by performing a frequency sweep test over the $0.628 \mathrm{rad} / \mathrm{s}-628 \mathrm{rad} / \mathrm{s}$ (i.e., $0.1-100 \mathrm{~Hz}$ ) frequencies, at a constant strain. Data were elaborated with RheoCompass ${ }^{\mathrm{TM}}$ software.

For the analysis, the same solutions as for $\mathrm{Zp}$ were tested. Before the analysis, solutions were sonicated to reduce air bubbles.

\subsection{SEM Analysis}

Scanning Electron Microscopy (SEM) analysis was performed with Zeiss Gemini 500 Field-Emission SEM (Carl Zeiss Microscopy, Oberkochen, Germany) at 5 kV. Polysaccharide samples of $50 \mathrm{mg}$ were freeze-dried in a $100 \mathrm{~mL}$ Falcon tube. The dried samples where broken with tweezers, deposited on SEM adhesive tape and sputtered with gold to enhance conductivity.

\subsection{Enzymatic Degradation Procedure}

$\mathrm{CH}$ (solution A): $75 \mathrm{mg}$ of sample were dissolved in $10 \mathrm{~mL}$ of PBS and stirred to obtain a completely solubilized solution. HA (solution B): $62 \mathrm{mg}$ of HA sample were dissolved in $5 \mathrm{~mL}$ of PBS and stirred for $16 \mathrm{~h}$. HA/Ch complex (solution C): $62 \mathrm{mg}$ HA were dissolved in $5 \mathrm{~mL}$ of solution $\mathrm{A}$. The final concentration of the polysaccharide $(\mathrm{HA} / \mathrm{Ch})$ was about $20 \mathrm{mg} / \mathrm{mL}(7.5 \mathrm{mg} / \mathrm{mL} \mathrm{CH}+12.5 \mathrm{mg} / \mathrm{mL} \mathrm{HA})$. For enzyme solution preparations, about $15 \mathrm{mg}$ of hyaluronidase were dissolved in about $1.5 \mathrm{~mL}$ of deionized water and stirred for $1 \mathrm{~h}(10 \mathrm{mg} / \mathrm{mL})$. Lysozyme: $75 \mathrm{mg}$ of lysozyme was dissolved in about $1 \mathrm{~mL}$ of deionized $\mathrm{H}_{2} \mathrm{O}$ and stirred for $1 \mathrm{~h}(75 \mathrm{mg} / \mathrm{mL})$. The solutions were stirred at $38^{\circ} \mathrm{C}$ in an oil bath for about $2 \mathrm{~h}$, before adding the enzyme solution. Different aliquots of solutions were collected at different times ( $15 \mathrm{~min}, 30 \mathrm{~min}, 1 \mathrm{~h}, 2 \mathrm{~h}, 4 \mathrm{~h}, 6 \mathrm{~h}, 24 \mathrm{~h}$ ) and heated at $100{ }^{\circ} \mathrm{C}$ for $5 \mathrm{~min}$, using a thermo-shaker, (BioSan, Riga, Latvia) to denature the enzyme. The solutions were diluted to different concentrations for HP-SEC-TDA analysis. The Ch solutions were diluted to $2 \mathrm{mg} / \mathrm{mL}$ with the mobile phase, whereas the solutions containing HA or HA/Ch were diluted to $0.5 \mathrm{mg} / \mathrm{mL}$ (calculated on the total amount of polysaccharide in solution) with the mobile phase. Before the HP-SEC-TDA analysis, all solutions were filtrated to remove the precipitated enzyme (LLG-Syringe filter, CA pore size $0.20 \mu \mathrm{m}$, $\oslash 13 \mathrm{~mm})$.

\section{Results}

\subsection{Molecular Weight Distribution}

Chromatographic profiles of HA and $\mathrm{Ch}$ are shown in Figure $1 \mathrm{a}, \mathrm{b}$, respectively. The samples had an elution time between 10 and $15 \mathrm{~mL}$, with a large a-symmetric bell-shape chromatographic peak, caused by a high polydisperse index.

Values of weight-average molecular weight $(\mathrm{Mw})$, number-average molecular weight (Mn), and molecular-weight dispersity (Đ; Mw/Mn) are reported in Table 1. In addition, values of the intrinsic viscosity value $(\eta)$, hydrodynamic radius $(\mathrm{Rh})$, and Recovery \%, derived from TDA, are also reported. To estimate the Recovery $\%$, the OmniSEC software computes actual concentration in each chromatographic slice, based on the $d n / d c$ value, and a detector constant for the RI. The values of $a$ and $\log k$, corresponding to the slope and intercept constants of the Mark-Houwink curve, respectively, are also reported. The results refer to the mean values of duplicate injections.

For the HA samples, a recovery value of $90 \%$ indicated that no material remained adsorbed in the columns, considering that the water content in the sample was about $10 \% w / w$; for $\mathrm{Ch}$, the values were close to $100 \%$, due to the low water content in the sample. The $Đ$ value for HA was lower than that for $\mathrm{Ch}$, indicating low molecular weight 
dispersion. However, the values were relatively high, indicating the presence of chains of different length.
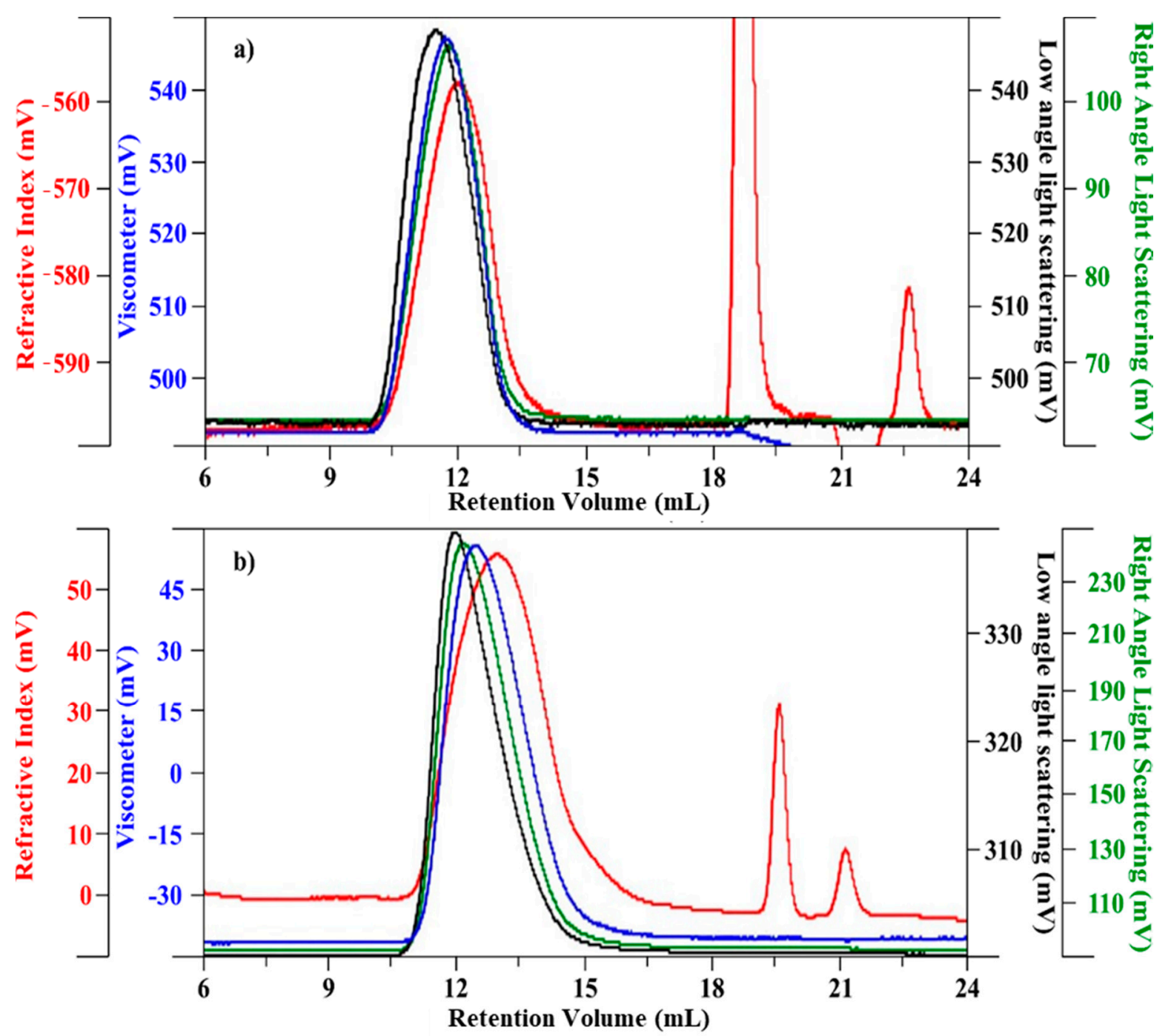

Figure 1. Chromatographic profile (red—refractive index; black—low laser light scattering; green—right angle light scattering; blue-viscometer). (a) HA, and (b) Ch.

Table 1. Main results of the HP-SEC-TDA analysis for the HA and Ch samples.

\begin{tabular}{|c|c|c|c|c|c|c|c|c|}
\hline Sample & Mw (kDa) & Mn (kDa) & Đ & a & $\log K$ & {$[\eta](d L / g)$} & $\mathrm{Rh}(\mathrm{nm})$ & Recovery\% \\
\hline HA & 992 & 660 & 1.5 & 0.69 & -2.9 & 17.4 & 63 & 90 \\
\hline $\mathrm{Ch}$ & 1020 & 554 & 1.8 & 0.68 & -3.6 & 3.0 & 34 & 96 \\
\hline
\end{tabular}

The HA/Ch complex (0.75:1.25 w/w) molecular weight was also determined by the same technique-results are visualized in Figure 2 As expected, due to very similar molecular weight, the two polysaccharides were eluted together, so it is important to evaluate the $d n / d c$ of the complex. From analysis on several dilutions of a HA/Ch complex, the refractive index increment $(d n / d c)$ was determined as 0.118 , through a linear regression.

Using 0.118 as $d n / d c$, the molecular weight analysis results are reported in Table 2. Molecular weight, dispersity, and hydrodynamic radius of the complex (Table 2) remained quite similar to those of the original polymers (Table 1). Generally, through gel permeation chromatography analysis, the average molecular weight of polymers increased due to cross-linked reactions or derivatizations. In the HA/Ch complex, only weak interactions 
between the two polysaccharides (hydrogen bonds and Van der Waals forces) are present, which are influenced by high salt concentration of mobile phase.

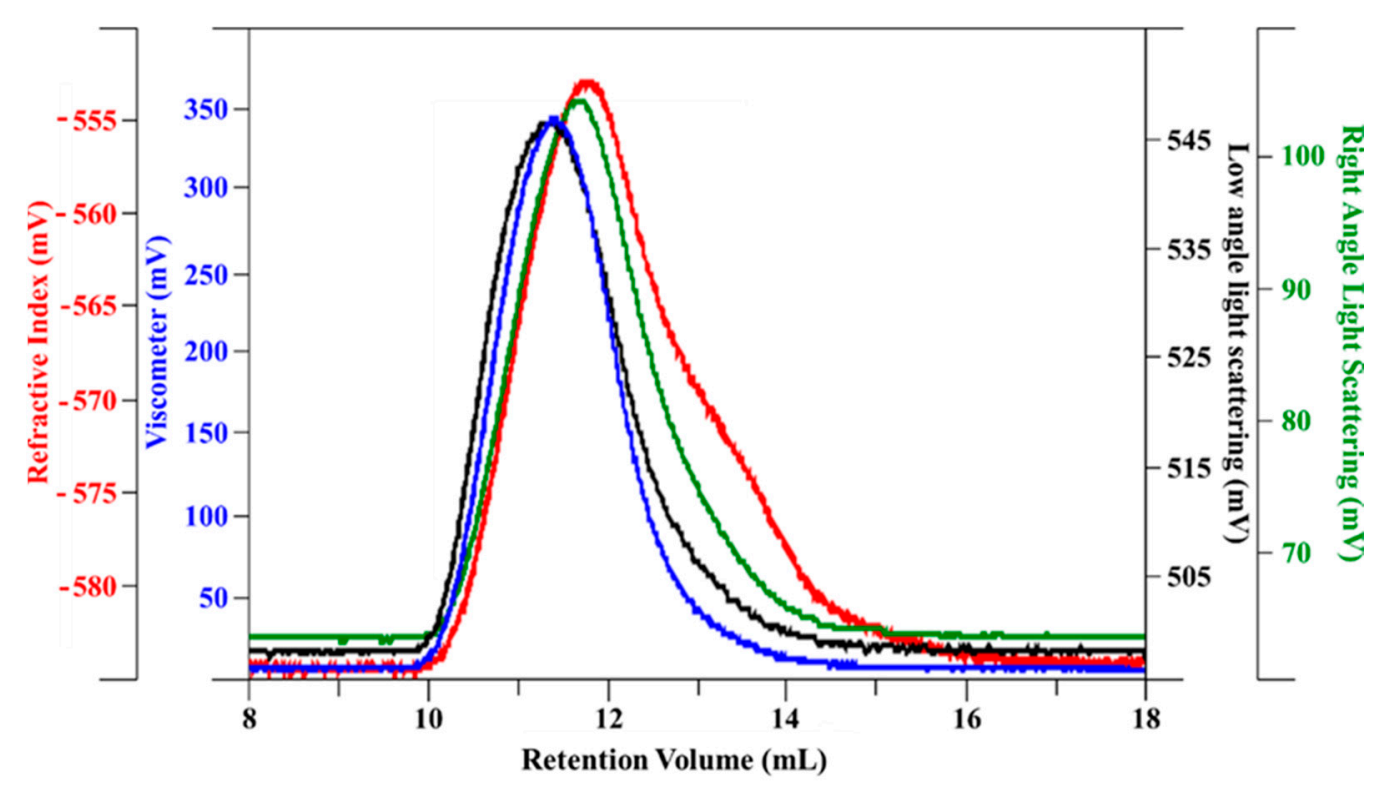

Figure 2. Chromatographic profile (red-refractive index; black—low laser light scattering; green—right angle light scattering; blue-viscometer) of the HA/Ch complex.

Table 2. HP-SEC-TDA HA/Ch complex results.

\begin{tabular}{cccccccc}
\hline Sample & Mw (kDa) & Mn (kDa) & Đ & a & $\log \mathbf{K}$ & [ๆ] (dL/g) & Rh (nm) \\
\hline $\begin{array}{l}\text { HA/Ch } \\
\text { complex }\end{array}$ & 1099 & 619 & 1.8 & 1.28 & -6.8 & 7.9 & 49 \\
\hline
\end{tabular}

\subsection{NMR Characterization}

Most of the properties of chitosan and its derivates, such as solubility and biodegradability, depend on the proportion between acetylated and non-acetylated glucosamine units, corresponding to degree of acetylation (DA), and eventually substitution degree (DS). NMR spectroscopy is one of the most accurate methods for determining the degree of acetylation for chitosan [38] and DS for Ch compounds [39].

Figure 3 shows the ${ }^{1} \mathrm{H}$ NMR spectrum of a Ch sample. The characteristic peaks are located at 3.32 and 3.40 ppm (black arrows Figure 3)-such signals represent the $\mathrm{H} 2$ of substituted deacetylate units ( $\mathrm{H} 2-\mathrm{NHR})$ and the hydrogens of the $\mathrm{CH}_{2}$ group involved in the amide bond (-NH-CH $\left.2^{-}\right)$, respectively. The $\mathrm{H} 2$ of unsubstituted deacetylate units $(\mathrm{H} 2-\mathrm{GlcN})$ appears at about $3.21 \mathrm{ppm}$. The peaks in the anomeric region, A (5.00 ppm) and B (4.88 ppm), in Figure 3 are attributed to H1 of the substituted and unsubstituted deacetylate units, respectively. These peaks and the $\mathrm{CH}_{3}$ signal of the acetyl group at 2.06 ppm (C, Figure 3) were used for the DA and DS calculation. In the anomeric region, the two sharp peaks were attributed to the anomeric protons of $\beta$-galactose side chains, at 4.57 ppm [17].

By assigning 300 to the integral of the signal related to the methyl group of acetyl (about $2.06 \mathrm{ppm})$, the percent $\mathrm{N}$-acetylation $(\% D A)$ and substitution degree $(\% D S)$ were evaluated, using Equations (1) and (2).

$$
\begin{gathered}
\% D A=\frac{\frac{C}{3}}{A+B+\frac{C}{3}} \cdot 100 \\
\% D S=\frac{A}{A+B} \cdot(100-\% D A)
\end{gathered}
$$




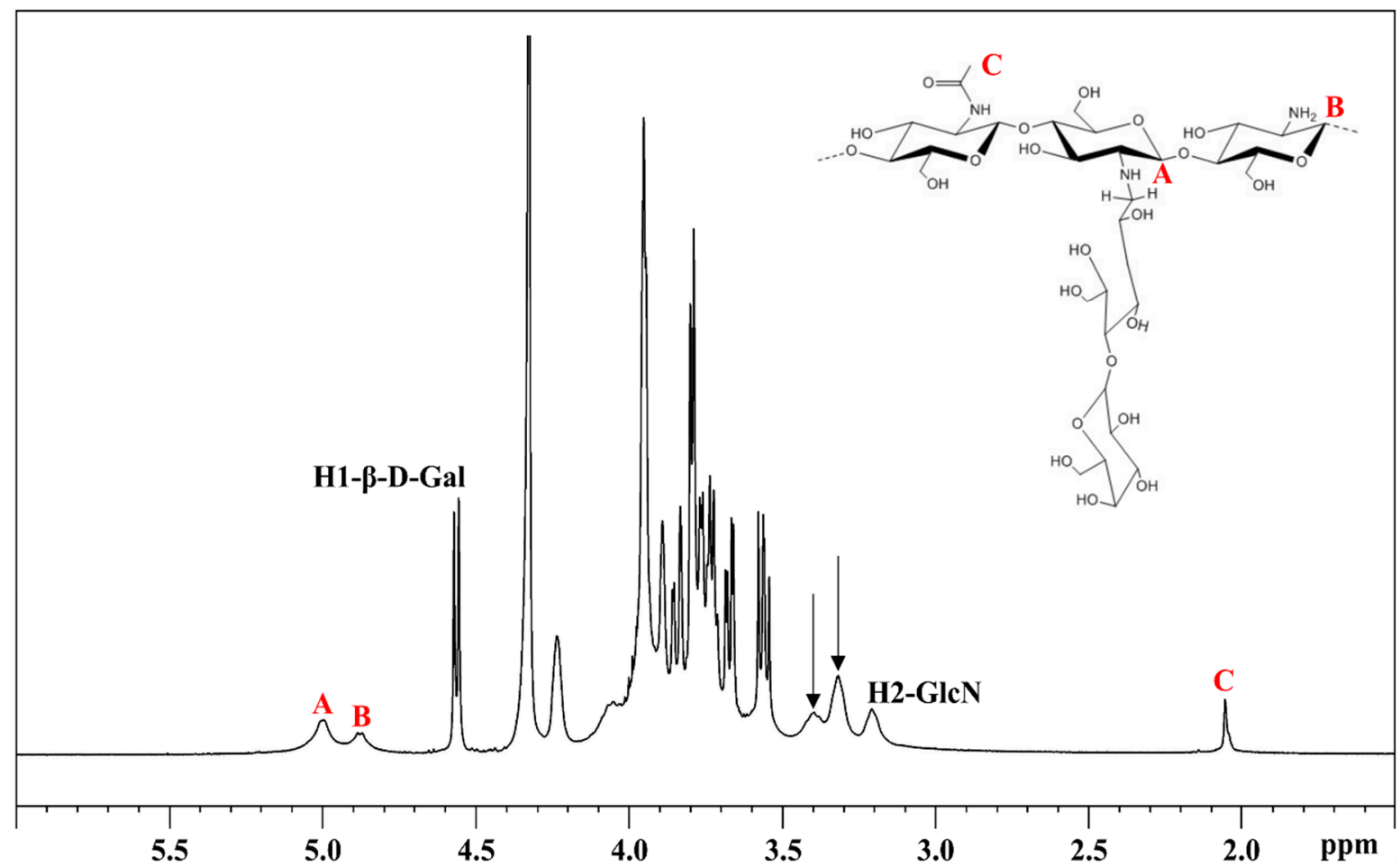

Figure $3 .{ }^{1} \mathrm{H}$ NMR spectrum of $\mathrm{Ch}$ in $\mathrm{D}_{2} \mathrm{O}$ at $343 \mathrm{~K}$.

From the integral values it was seen that in the Ch sample, $D A$ and $D S$ were $7.5 \%$ and $59 \%$, respectively.

To confirm the peak attributions and to verify that the integrated signals involved in quantification corresponding to the unique function units, the ${ }^{1} \mathrm{H}-{ }^{13} \mathrm{C} H S Q \mathrm{C}$ spectrum was acquired (Figure 4). The 2D spectrum confirmed that the anomeric and methyl peaks in the ${ }^{1} \mathrm{H}$ spectrum corresponded to one peak in the ${ }^{13} \mathrm{C}$ dimension, and that ${ }^{13} \mathrm{C}$ chemical shifts were consistent with the attributed signals of product [17].

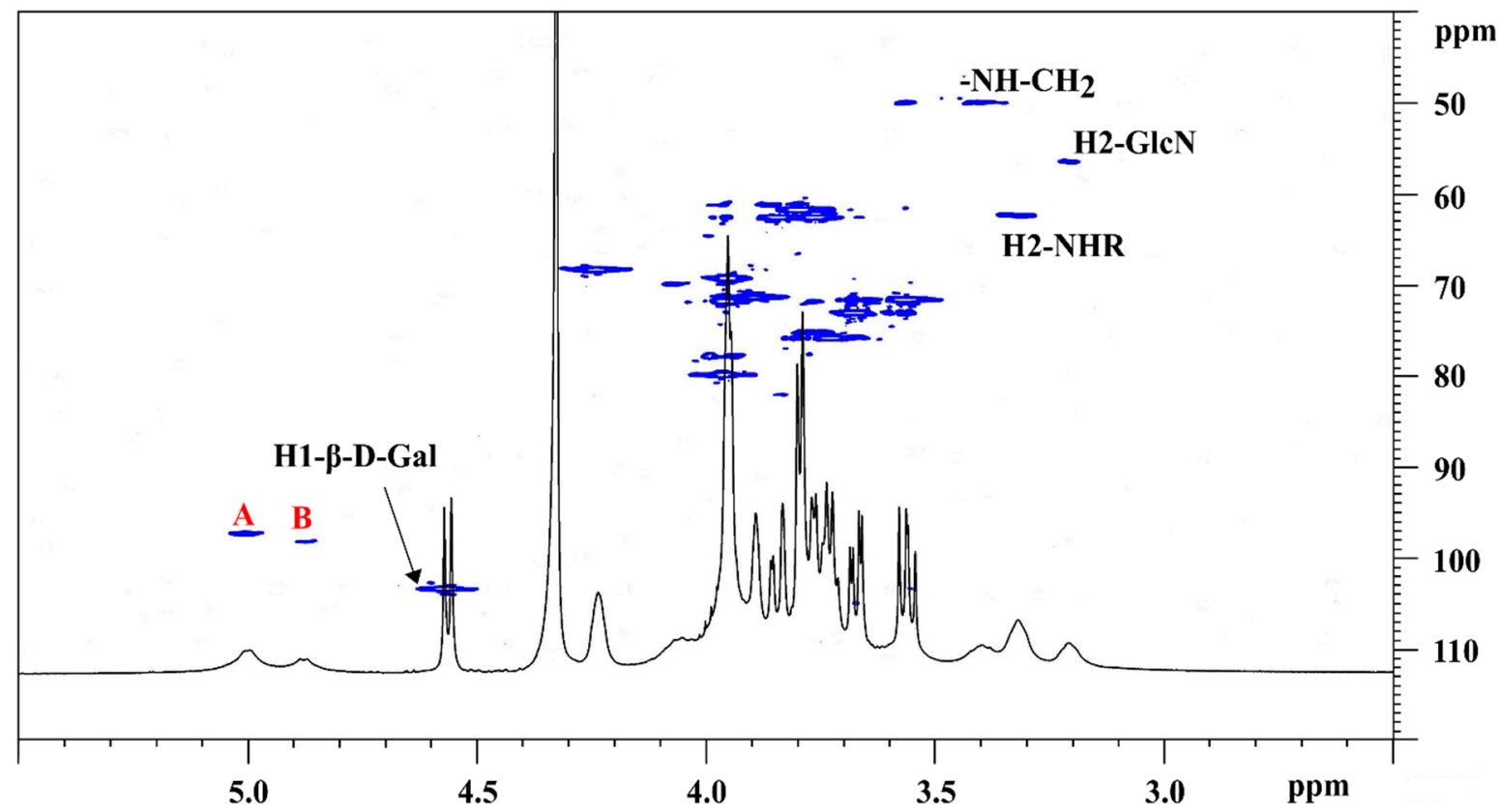

Figure $4 .{ }^{1} \mathrm{H}_{-}{ }^{13} \mathrm{C}$ HSQC NMR spectrum of $\mathrm{CH}$ in $\mathrm{D}_{2} \mathrm{O}$ at $343 \mathrm{~K}$. 
Pulsed field gradient (PFG) diffusion ordered spectroscopy (DOSY) is the translational diffusion of dissolved molecules. In addition to the overall molecular size and shape, the diffusion coefficient magnitude provides direct information on molecular dynamics, including intermolecular interactions [40], aggregation, conformational changes [41,42], and viscosity [43]. DOSY processing is a particularly suitable technique for complex samples, since it provides a direct correlation of translational diffusion to the chemical shift in the second dimension. Therefore, a prior separation of complex components is not required [44,45]. A DOSY experiment is represented in a 2D spectrum, with chemical shift along one axis and the diffusion coefficients along the other [46,47].

In this study, DOSY was used to evaluate the interaction between HA and $\mathrm{Ch}$ in the complex. The outcomes of the DOSY analysis for all samples are visualized in a 2D map in Figure 5a.

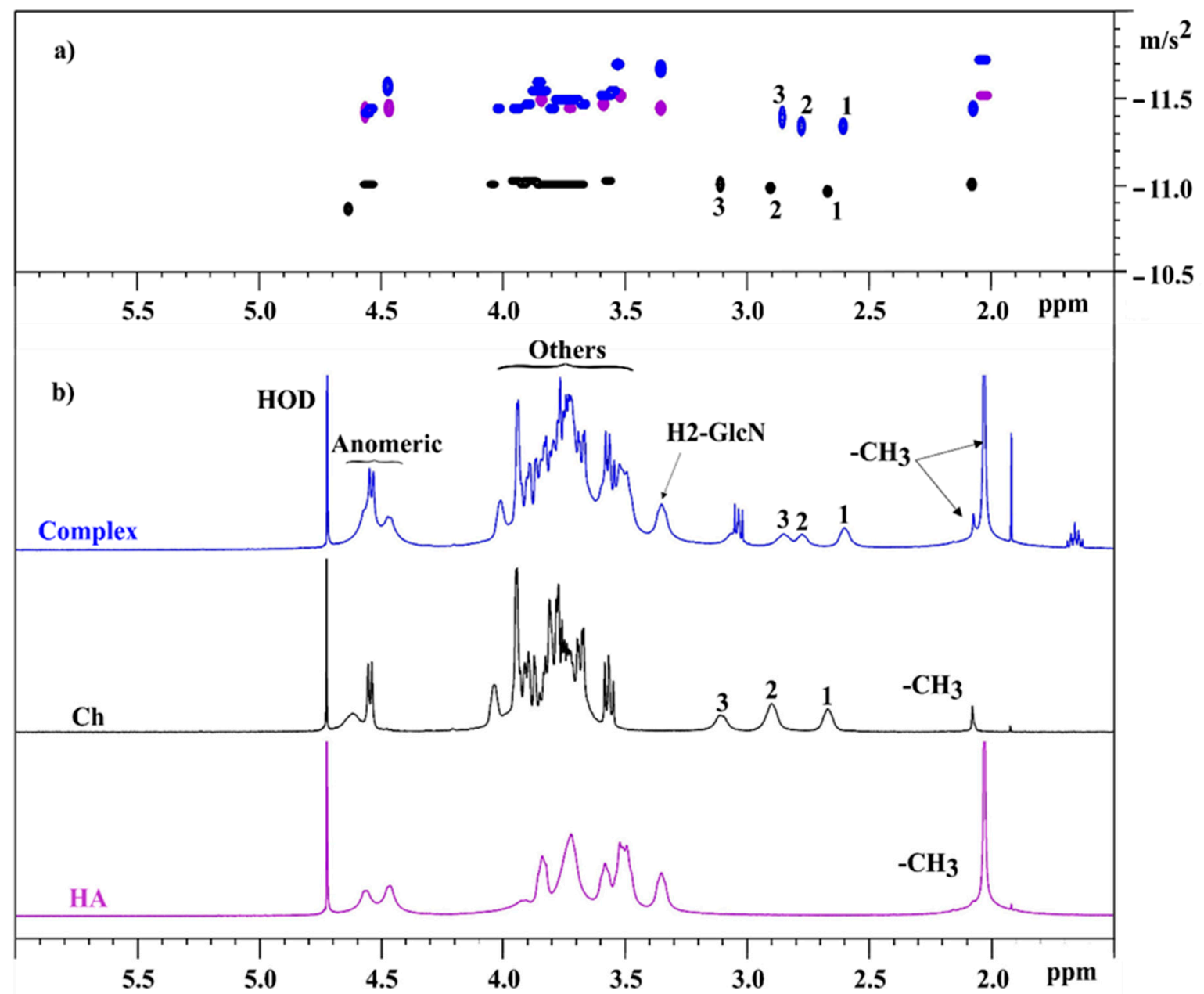

Figure 5. (a) DOSY and (b) ${ }^{1} \mathrm{H}$ spectra of HA (purple), Ch (black), and complex (blue).

For the HA and Ch samples, there is only one population with the same diffusion coefficient, due to a unique molecular weight. For the HA/Ch complex, the results showed different diffusive fronts, due to different hydrodynamic radius of (5a) the HA resonances, and (5b) the resonances due to $\mathrm{Ch}$ moiety. The different chemical shift for 1,2, and 3 signals were related to different small $\mathrm{pH}$ of solutions in the presence of HA. Usually, chemical shift of main chain protons, involved in the amino bond (H2) are highly sensitive to the protonation equilibrium [17]. The D values, shown in Table 3, were determined for the peaks corresponding to the components of the complex. 
Table 3. DOSY results of HA, Ch, and HA/Ch complex $\left(\mathrm{D}=\mathrm{H}_{2} \mathrm{O} 2.25 \times 10^{-9} \mathrm{~m}^{2} / \mathrm{s}\right.$; $\left.\mathrm{D}=\mathrm{TSP}: 6.50 \times 10^{-10} \mathrm{~m}^{2} / \mathrm{s}\right)$.

\begin{tabular}{|c|c|c|c|c|c|c|}
\hline \multirow{3}{*}{ Peak } & \multicolumn{2}{|c|}{ HA } & \multicolumn{2}{|c|}{ Ch } & \multicolumn{2}{|c|}{ HA/Ch Complex } \\
\hline & ${ }^{1} \mathbf{H}$ ppm & $\mathrm{D}\left(\mathrm{m}^{2} / \mathrm{s}\right)$ & ${ }^{1} \mathrm{H}$ ppm & $\mathrm{D}\left(\mathrm{m}^{2} / \mathrm{s}\right)$ & ${ }^{1} \mathrm{H}$ ppm & $\mathrm{D}\left(\mathrm{m}^{2} / \mathrm{s}\right)$ \\
\hline & 2.03 & $1.48 \times 10^{-12}$ & 2.07 & $6.89 \times 10^{-12}$ & 2.03 & $6.35 \times 10^{-13}$ \\
\hline 1 & - & - & 2.73 & $7.05 \times 10^{-12}$ & 2.60 & $2.64 \times 10^{-12}$ \\
\hline 2 & - & - & 2.96 & $7.11 \times 10^{-12}$ & 2.77 & $2.89 \times 10^{-12}$ \\
\hline 3 & - & - & 3.14 & $7.53 \times 10^{-12}$ & 2.85 & $3.05 \times 10^{-12}$ \\
\hline H2-GlcA & 3.36 & $1.61 \times 10^{-12}$ & - & - & 3.35 & $7.51 \times 10^{-13}$ \\
\hline Anomeric & $4.40-4.60$ & $1.72 \times 10^{-12}$ & $4.50-4.55$ & $6.60 \times 10^{-12}$ & $4.40-4.60$ & $1.86 \times 10^{-12}$ \\
\hline others & $3.51-3.84$ & $1.51 \times 10^{-12}$ & $3.54-4.04$ & $6.65 \times 10^{-12}$ & $3.54-4.04$ & $1.60 \times 10^{-12}$ \\
\hline
\end{tabular}

The average $\mathrm{D}$ value of $\mathrm{HA}$ was lower than $\mathrm{Ch}$, despite having similar Mw values. In this case, DOSY was particularly successful in distinguishing among different molar diffusivities, due to the different hydrodynamic radii, confirming the HP-SEC-TDA results. In the HA/Ch complex, the D values of the HA component remained almost constant, meanwhile the $\mathrm{Ch}$ diffusion coefficients increased, with values analogous to HA.

\subsection{Rheological Properties}

Rheology as reported by Ambrosio et al. [48], is a useful tool to explore the relationships between the mechanical behavior and chemical properties of $\mathrm{HA}$, or other biopolymer solutions. In our study, the flow behavior and viscoelastic measurement were evaluated to understand the difference in the rheological properties of HA and Ch solutions with their complex.

The variation of the viscosity as a function of the shear rate were acquired; in Figure $6 \mathrm{a}$ the viscosity curves, with a shear rate $(\gamma)$ ranging from $0.1 \mathrm{~s}^{-1}$ to $100 \mathrm{~s}^{-1}$, are reported.
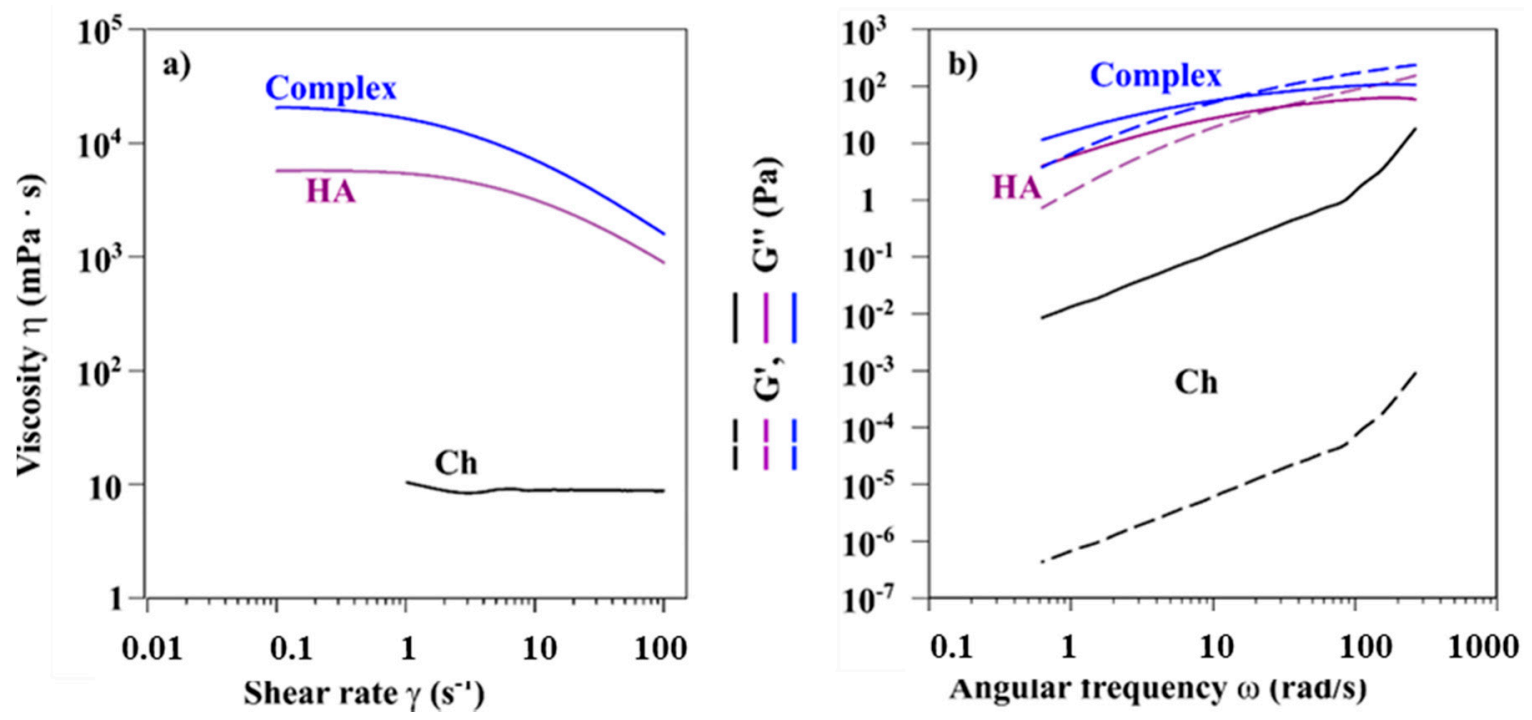

Figure 6. (a) Viscosity curves of the Ch, HA, and HA/Ch complex. Due to low viscosity, data for Ch were only acquired in the range (1-100) s ${ }^{-1}(\mathbf{b})$. Frequency sweep test of the $\mathrm{Ch}(\gamma=20 \%), \mathrm{HA}$, and the HA/Ch complex $(\gamma=2 \%)$.

HA and Ch (black and purple curves in Figure 6a, respectively) showed different behaviours. Ch viscosity remained constant at a value of $8.8 \mathrm{mPa}$ s over the entire tested shear rate range, thus showing ideal viscous flow behaviour. Such behaviour was mainly related to the sample concentration and substitution degree of chitosan-according to previous results [49]. The pseudoplasticity was inversely proportional to DS and directly correlated to the concentration of sample. For HA, viscosity was shear-dependent, viscosity decreased as $\gamma$ increased, in agreement with a pseudoplastic behaviour [48]. For the 
complex, shear-thinning behaviour was also observed. Note that the viscosity values were higher than that for pure HA.

The rheological tests were also performed in the oscillation mode, to evaluate both the storage modulus $\left(G^{\prime}\right)$ and the loss modulus $\left(G^{\prime \prime}\right)$. The strain sweep test (data not shown) was initially performed to evaluate the LVE zone, where the intrinsic sample structural properties are independent of the applied strain:2\% (HA and Complex) and 20\% (Ch) strain value was selected for subsequent frequency sweeps tests. In Figure $6 b$, values of $G^{\prime}$ and $G^{\prime \prime}$ as function of the angular frequency for the $\mathrm{Ch}, \mathrm{HA}$, and the complex are reported. In the investigated frequency range (from $0.628 \mathrm{rad} / \mathrm{s}$ to $628 \mathrm{rad} / \mathrm{s}$ ), the mechanical spectrum of Ch showed that $G^{\prime \prime}$ was greater than $G^{\prime}$, with both moduli strongly dependent on the frequency, as typically a liquid-like (viscous) behavior dominates over the solid-like (elastic) character. Differently, HA and HA/Ch presented a "weak gel" or viscoelastic behavior with $G^{\prime}$ and $G^{\prime \prime}$, which became less dependent on the frequency and the crossover point, when $G^{\prime}=G^{\prime \prime}$, was observed. This suggests that at high frequencies, when $G^{\prime}>G^{\prime \prime}$, the material show a predominant solid-like behavior.

The angular frequency values, $\omega_{c}$, and the corresponding $G^{\prime}=G^{\prime \prime}$ values to the crossover point data are reported in Table 4.

Table 4. Rheological measurements-evaluation of G' and G" crossover.

\begin{tabular}{ccc}
\hline Sample & $\begin{array}{c}\text { Angular Frequency } \omega_{\mathrm{c}} \\
(\mathrm{rad} / \mathrm{s})\end{array}$ & $\begin{array}{c}\text { Crossover Point } \\
\mathbf{G}^{\prime}=\mathbf{G}^{\prime \prime}(\mathbf{P a})\end{array}$ \\
$\mathrm{Ch}$ & n.d. ${ }^{1}$ & n.d. $^{1}$ \\
$\mathrm{HA}$ & 30 & 44 \\
$\mathrm{HA} / \mathrm{Ch}$ & 13 & 63 \\
\hline
\end{tabular}

${ }^{1}$ value not detected in the frequency range investigated.

\subsection{Zeta Potential}

$\mathrm{Zp}$, a parameter typically obtained by model-dependent transformation of the measured electrophoretic mobility, is a parameter used to estimate the magnitude of the electrostatic repulsion or attraction between particles. By measuring the surface charge, the stability of nanosuspensions, particles, and polymers in solution can be determined [50]. A large positive or negative $\mathrm{Zp}$ value, with values $>+25 \mathrm{mV}$ or $<-25 \mathrm{mV}$, indicate good stability due to electrostatic repulsion of individual particles; a lowZp value can result in particle aggregation and flocculation due to the van der Waals attractive forces [51-53]. The $\mathrm{Zp}$ is frequently used to understand polysaccharide-protein complexation [54].

In this study, the $\mathrm{Zp}$ values of solutions of the $\mathrm{Ch}, \mathrm{HA}$, and $\mathrm{HA} / \mathrm{Ch}$ complex were determined; the results are reported in Table 5. The Ch and HA samples were studied at concentrations of 7.5 and $12.5 \mathrm{mg} / \mathrm{mL}$, respectively, which reflect the concentrations of the individual samples in the complex.

Table 5. $\mathrm{Zp}$ values for $\mathrm{HA}, \mathrm{Ch}$, and complex.

\begin{tabular}{ccc}
\hline Sample & Concentration $(\mathbf{m g} / \mathbf{m L})$ & Zp $(\mathbf{m V})$ \\
\hline HA & 12.5 & -33.74 \\
Ch & 7.5 & 0.03 \\
HA/Ch complex & 20.0 & -23.28 \\
\hline
\end{tabular}

HA showed a negative $\mathrm{Zp}$ value, which was consistent with its anionic nature to the presence of carboxylic groups. Low zeta potential values provided an electrostatic repulsion that led to the formation of suitable stability in solution. Else, the $\mathrm{Zp}$ value of Ch was zero, indicating a slightly positive surface charge, close to zero, in agreement with the chemical structure. When the two polysaccharides were mixed, the $\mathrm{Zp}$ of the complex was negative and homogeneous. The value of about $-23 \mathrm{mV}$ meant that the 
complex in solution was stable without any macro-aggregation phenomena that could induce precipitation.

\subsection{SEM}

SEM analysis was performed to assess the morphological features of the HA/Ch complex [55], after a freeze-drying process. In the first step of freeze-drying, the waterbased solutions (or suspensions) were first frozen-ice nucleated and concentrated the solute (or suspended matter) in the regions between the growing crystals. In the second step, ice was removed via direct sublimation at low pressure, avoiding the intermediate liquid phase, and leaving a porous morphology. The process is widely used to create porous materials using biopolymer [56-58]. The final morphology depends on the specificmaterial, and is controlled by many parameters of the freezing process [59], including sample size and shape, cooling rate, cooling temperature, process time, etc.

Figure 7 illustrates the specific characteristics of the HA/Ch complex that were compared to the single components of $\mathrm{Ch}$ and HA.
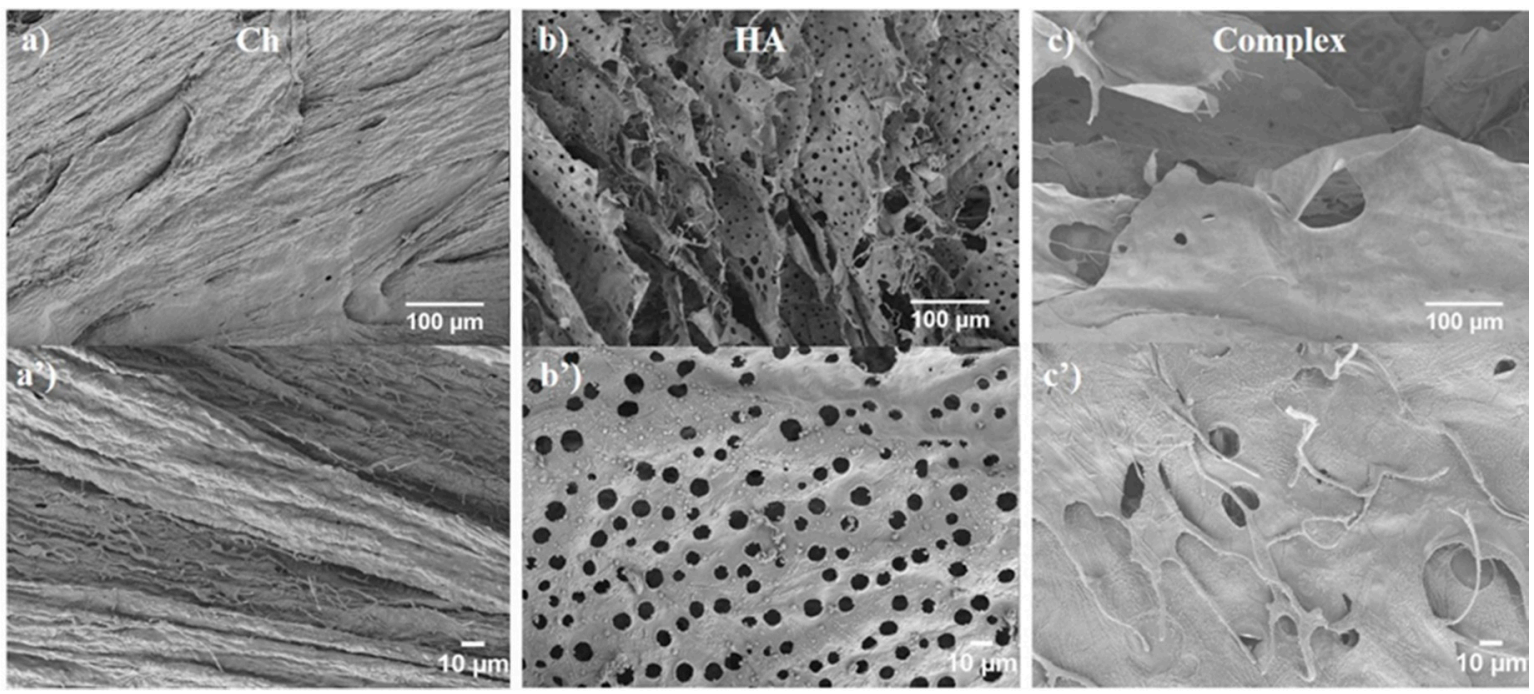

Figure 7. SEM analysis of (a) Ch (magnification 150×); (a') Ch (magnification 500×); (b) HA (magnification 150×); (b') HA (magnification 500×); (c) Complex (magnification 150×); and ( $\left.\mathbf{c}^{\prime}\right)$ Complex (magnification 500×).

Ch (Figure $7 \mathrm{a}, \mathrm{a}^{\prime}$ ) showed a compact structure with a fibrous appearance, causing a rough texture on the $\mathrm{Ch}$ surface. HA presents even more clearly a lamellar structure (Figure $7 \mathrm{~b}, \mathrm{~b}^{\prime}$ ), which is characteristic of an ice-templated process-the structure was oriented parallel to the temperature gradient (i.e., from the skin to the sample centre), along which the ice crystal grew. HA walls were characterized by a pore regular pattern, with a characteristic diameter of $\sim 10 \mu \mathrm{m}$. Such pores might also be related to ice-templating, with holes forming due to the secondary crystal growth, perpendicular to the primary crystal growth direction.

The HA/Ch composite (Figure 7c, $\mathrm{c}^{\prime}$ ) showed a compact and smooth surface, where fibers were visible on the top of the surface. The material was made of a lamellar structure with the holes between 10 and $20 \mu \mathrm{m}$ as diameter. Similar to Zhang et al. [60], who investigated the structure of porous chitosan/HA/sodium glycerophosphate hydrogel systems, the material appeared homogeneous overall, and phase separation at the microscale was not observed. As such, we could confirm good compatibility between $\mathrm{Ch}$ and HA in the complex.

\subsection{Enzymatic Degradation}

The HA/Ch enzymatic degradation with lysozyme and hyaluronidase was studied. Such tests provide information on the polysaccharide stability in a physiological environ- 
ment. The samples incubated at different times were analyzed. The Mw values vs. time, determined by chromatographic elaboration, are shown in Figure 8.
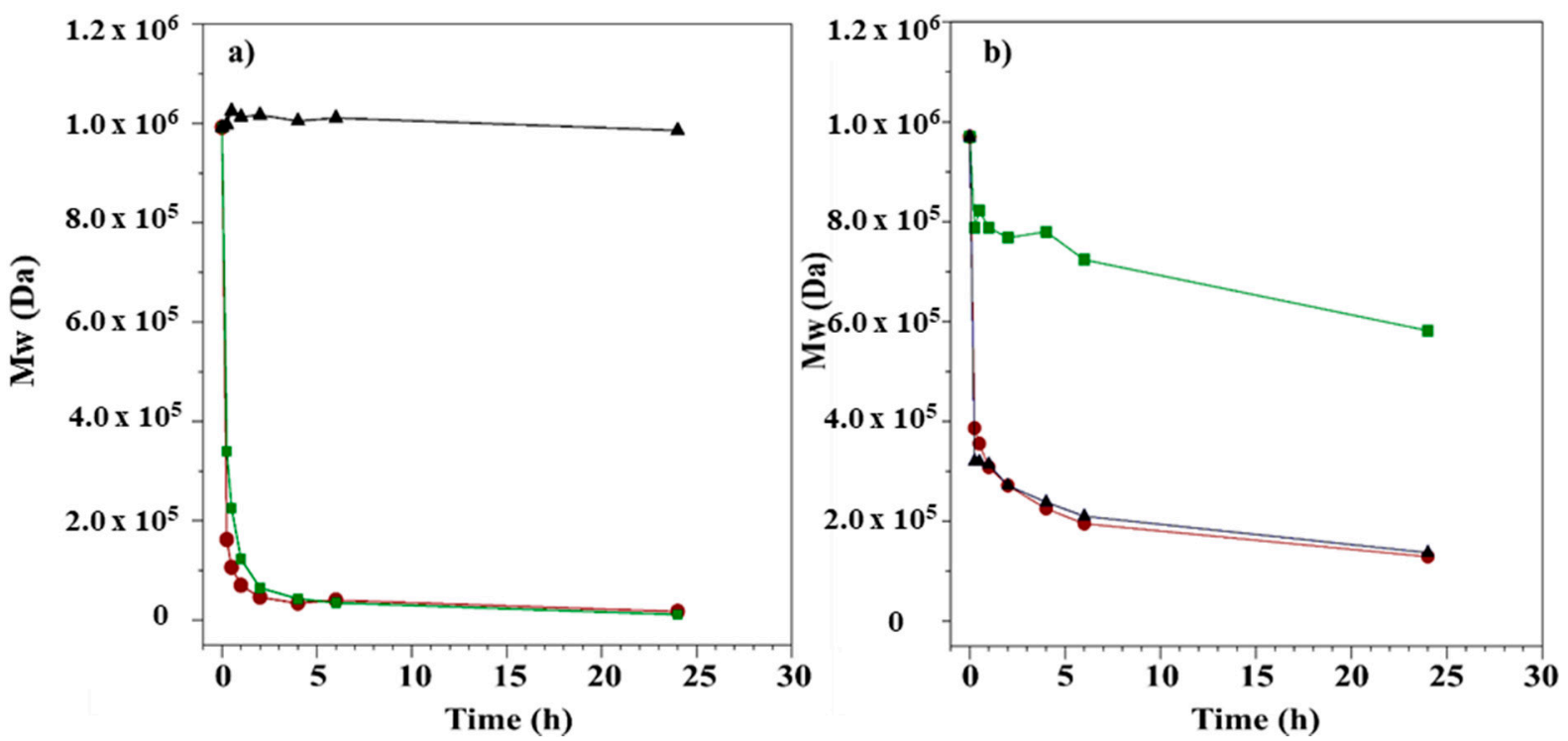

Figure 8. (a) HA and (b) Ch kinetic degradation with HAse (green curves), Lys (black curves), and a mix of enzymes (red curves) over $24 \mathrm{~h}$.

The HA treatment (Figure 8a, green line) resulted in a substantial reduction of $\mathrm{Mw}$ indicating depolymerization, and such depolymerization took place very quickly during the initial $3 \mathrm{~h}$, this indicated that the enzymatic hydrolysis was an endo-action. After $3 \mathrm{~h}$, degradation slowed down, probably due to the inhibition of the enzyme activity by the end products, and the reaction was completed after $24 \mathrm{~h}$, at the end of which a reduction of the Mw of $98 \%$ was observed (from $992 \mathrm{kDa}$ to $14 \mathrm{kDa}$ ). In the case of Lys (Figure 8a, black line), the enzyme did not have any degradation effect, and $\mathrm{Mw}$ remained constant for the incubation time $(24 \mathrm{~h})$. As expected, the presence of Lys in complex with HAse (Figure 8a, red line) had a mild effect on the HA hydrolysis, showing a slightly different initial degradation rate, but the end point was the same.

For Ch, in the enzymatic degradation with Lys (Figure 8b, black line), the Mw decreased slowly and, after $24 \mathrm{~h}$ of incubation, the value was reduced by $86 \%$ (from $970 \mathrm{kDa}$ to $137 \mathrm{kDa}$ ); with HAse (Figure $8 \mathrm{~b}$, green line) a small reduction of $\mathrm{Mw}$ was observed, at about $20 \%$, which was in agreement with the lack of a specific substrate for this enzyme. The decrease of $\mathrm{Mw}$ was the same with the complex of enzymes than with Lys aloneas expected, the "driving force" for the degradation of Ch was Lys but the presence of hyaluronidase seemed to induce an effect on the first part of hydrolysis process.

To study how the interactions between HA and Ch could affect the enzymatic activity, the complex was hydrolyzed. The results with HAse and Lys individually and finally with enzymatic complex are shown in Table 6. All chromatograms of solutions until $6 \mathrm{~h}$ of incubation present only one peak, derived from $\mathrm{HA}$ and $\mathrm{Ch}$, due to the very similar molecular weight. Consequently, the $\mathrm{Mw}$ and $[\eta]$ values are related to the complex, imposing the $d n / d c$ of 0.118 (see HP-SEC-TDA results section).

After $6 \mathrm{~h}$, the Mw was reduced by about $70 \%$ with HAse, and $20 \%$ and $92 \%$ with Lys and with HAse + Lys, respectively. Therefore, the enzyme activity was not affected by the combination of the two polysaccharides.

After $24 \mathrm{~h}$ of incubation, the chromatograms present two distinct peaks (Figure 9), one related to the HA component and the other one attributed to $\mathrm{Ch}$, so $\mathrm{Mw}$ and [ $\eta]$ for each polysaccharide could be determined, using the specific $d n / d c$ values. The results are presented in Table 7 . 
Table 6. HP-SEC-TDA results of the HA/Ch complex degradation.

\begin{tabular}{ccccccc}
\hline & \multicolumn{2}{c}{ HAse } & \multicolumn{2}{c}{ Lys } & \multicolumn{2}{c}{ HAse + Lys } \\
\hline Time (h) & Mw (kDa) & {$[\boldsymbol{\eta}] \mathbf{~ d L / g}$} & Mw (kDa) & {$[\eta]$ dL/g } & Mw (kDa) & {$[\eta]$ dL/g } \\
\hline 0 & 1099 & 10.0 & 1099 & 10.0 & 1099 & 10.0 \\
0.25 & 406 & 2.0 & 902 & 7.3 & 192 & 1.6 \\
0.30 & 377 & 1.7 & 875 & 7.3 & 167 & 1.2 \\
1 & 370 & 1.5 & 884 & 7.4 & 150 & 1.0 \\
2 & 352 & 1.4 & 904 & 7.6 & 128 & 0.9 \\
4 & 345 & 1.3 & 878 & 7.4 & 104 & 0.7 \\
6 & 331 & 1.3 & 884 & 7.7 & 95 & 0.6 \\
\hline
\end{tabular}

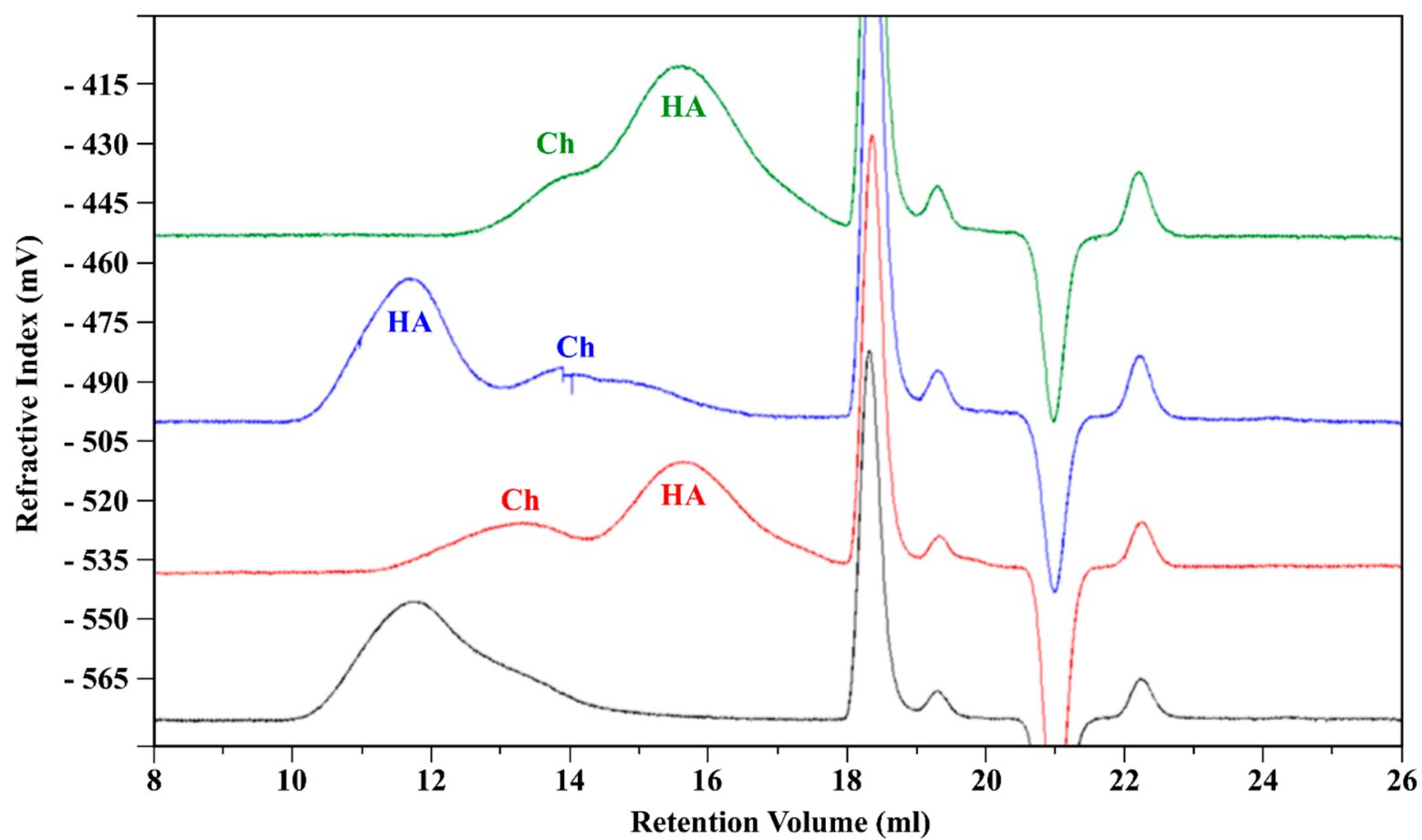

Figure 9. RI signal from the HP-SEC-TDA analysis of the HA/Ch complex at $t=0$ (black) and after degradation $t=24 \mathrm{~h}$ with HAse (red), Lys (blue), and a mix of enzymes (green).

Table 7. HP-SEC-TDA results of the HA/Ch complex degradation after $24 \mathrm{~h}$.

\begin{tabular}{ccccccc}
\hline & \multicolumn{2}{c}{ HAse } & \multicolumn{2}{c}{ Lys } & \multicolumn{2}{c}{ HAse + Lys } \\
\hline & Mw (kDa) & {$[\mathbf{h}] \mathbf{d L} / \mathbf{g}$} & $\mathbf{M w} \mathbf{( k D a )}$ & {$[\mathbf{h}] \mathbf{d L} / \mathbf{g}$} & $\mathbf{M w ~ ( k D a )}$ & {$[\mathbf{\eta}] \mathbf{d L} / \mathbf{g}$} \\
\hline HA & 16 & 0.4 & 955 & 15 & 19 & 0.3 \\
Ch & 620 & 2.3 & 155 & 1.6 & 220 & 1.1 \\
\hline
\end{tabular}

The Mw values were very similar to the results obtained for the solution aliquots containing only HA or $\mathrm{Ch}$, at $24 \mathrm{~h}$, suggesting that the co-presence of both polysaccharides did not affect the enzymatic action.

\section{Discussion}

The polyelectrolyte complex in the aqueous medium interacts and self-assembles by electrostatic interactions. Therefore, the development of new stable formulations, constituting polyelectrolyte, requires an in-depth characterisation of the interactions to obtain biodegradable and biocompatible products with unique properties, without losing the poly- 
mers inherent characteristics. In the present work, efficacies analytical approaches were set up to characterize the HA/Ch complex and to evaluate its stability toward enzymes.

The interaction between HA and $\mathrm{Ch}$ was affected by the structural peculiarity of each polysaccharide. With regards to HA, the chemical structure was well-defined, meanwhile for $\mathrm{Ch}$, the DS and DA were variable. Generally, the proportion of glucosamine residues in chitosan had a significant influence on their various properties. In particular, the distribution of N-acetyl groups along the biopolymer chain might influence the solubility of the polymer and the inter-chain interactions, due to the hydrogen bonds and the hydrophobic character of the acetyl group. Moreover, the derivatization of chitosan with alkyl groups induced high mobility side chains, causing them to be highly hydrated. It follows that the DS and DA of Ch are important parameters for the property of the polysaccharide in solution and for the interaction with HA. A schematic representation of how $\mathrm{Ch}$ and HA interact to form a complex is given in Figure S1.

A quantitative ${ }^{1} \mathrm{H}$ NMR method was applied to determine the DA and DS of $\mathrm{Ch}$. The Ch sample with DA and the DS values of $7.5 \%$ and $59 \%$, respectively, is soluble in water at neutral $\mathrm{pH}$ and it presents a low viscosity, as compared to the same molecular weight of HA, as shown by the HP-SEC-TDA results (Table 1) and the viscosity curves (Figure 6a). HA was approximately 6 times more viscous in terms of intrinsic viscosity than $\mathrm{Ch}$, and the hydrodynamic radius for the negative charge polysaccharide was double, as compared to $\mathrm{Ch}$, although the molecular weights were quite similar. This behavior was confirmed by the DOSY NMR experiment (Table 3). Indeed, the average D values of HA were lower than those of $\mathrm{Ch}$, indicating a lower mobility due to higher viscosity. When the two polysaccharides were mixed, anaverage molecular weight distribution between HA and Ch was obtained, which maintained a high intrinsic viscosity value (Figure 2, Table 2).

The homogeneity of the complex was demonstrated by the Zp measurements (Table 5) -one $\mathrm{Zp}$ value was observed and through the comparison of the results, the $\mathrm{HA} / \mathrm{Ch}$ complex $\mathrm{Zp}$ was about $-23 \mathrm{mV}$, lower than that obtained for the HA alone $(-34 \mathrm{mV})$, indicating that the negative charges of HA were partially reduced in the presence of $\mathrm{Ch}$, due to the phenomena of secondary interaction between the polysaccharides. The strict interaction between HA and Ch was also demonstrated by DOSY:the D values of HA and $\mathrm{Ch}$ in the complex were similar (Table 3).

It clearly appears that by mixing the two polysaccharides, an interesting modulation of the viscoelastic properties could be easily obtained (Figure $6 \mathrm{~b}$ ). The mechanical spectra of the solutions prepared using only HA or Ch represent two different behaviors-the HA solution had a relevant viscoelastic character, whereas the $\mathrm{Ch}$ sample presented a more evident liquid/elastic character. Finally, the HA/Ch solution showed the highest values of both elastic and viscous moduli, with a shift toward higher frequency of the crossover point (Table 4).

SEM analysis on the Ch/HA composite supported the data that suggest an intimate mixing of the components, revealing characteristic features of the individual polysaccharide, such as lamellae, fibers, and pores.

We demonstrated that $\mathrm{HA}$ and $\mathrm{Ch}$, solubilized together, can generate secondary interactions that modified the chemico-physical properties of polysaccharides. To verify if these phenomena could affect the biocompatibility, the stability toward enzymatic actions was evaluated, comparing the results obtained from a single component preparation and the complex of HA/Ch. While the HA was fully degraded by Hyaluronidase and was not hydrolyzed by Lysozyme, Ch was mildly degraded by Hyaluronidase, and was fully hydrolyzed by Lysozyme. Using the Hyaluronidase and Lysozyme complex with each polysaccharide, the Mw values were the same for those obtained with the specific enzymes. This meant that there was no cooperative effect in the degradation process. Analyzing the $\mathrm{HA} / \mathrm{Ch}$ complex, HA hydrolysis was not modified by $\mathrm{Ch}$, wheras $\mathrm{Ch}$ appeared more resistant to enzyme hydrolysis in presence of HA. Our hypothesis suggests that the penetration of the enzymes to the network $\mathrm{HA} / \mathrm{Ch}$, and in particular, the availability of $\mathrm{Ch}$ molecules to 
the active site of the enzymes were slightly hindered; however, but the hydrolysis processes was maintained.

\section{Conclusions}

In this study, we investigated the supramolecular structuring of a HA/Ch complex using diverse analytical methods. The HA/Ch solution was characterized in terms of physicochemical properties. The supramolecular complex showed interesting rheological properties and promising preliminary evidence for biocompatibility-monodisperse molecular weight distribution, high viscosity, negative charge, degradation by specific enzyme, such as Hyaluronidase and Lysozyme. Due to the wide range of applications in biomedicine and biotechnology, the development of such polyelectrolyte complexes is of scientific and technological interest. Such an analytical approach would facilitate the development of new formulations, demonstrating the interactions with the different components.

Supplementary Materials: The following are available online at https:/ / www.mdpi.com/2218-273 X/11/3/389/s1, Figure S1: Schematic interaction between HA and Ch in Phosphate buffer saline.

Author Contributions: Conceptualization, S.B. and G.B.; investigation, R.L., I.T., C.A., and C.C.; writing - original draft preparation S.B. and G.B.; funding acquisition, G.B. All authors have read and agreed to the published version of the manuscript.

Funding: The research was partially funded by G. Ronzoni foundation.

Data Availability Statement: The data that support the findings of this study are available from the corresponding author upon reasonable request.

Acknowledgments: C.A. acknowledges partial support from the Italian Ministry for University and Research through the Rita Levi Montalcini fellowship for young researchers. C.A. and I.T. acknowledge technical support by Tiziano Catelani for SEM imaging. S.B., R.L., and C.C. acknowledge technical support by Regina Fratiello for HP-SEC-TDA analyses.

Conflicts of Interest: The authors declare no conflict of interest.

\section{References}

1. Aravamudhan, A.; Ramos, D.M.; Nada, A.A.; Kumbar, S.G. Natural Polymers: Polysaccharides and Their Derivatives for Biomedical Applications; Elsevier Inc.: Amsterdam, The Netherlands, 2014; ISBN 9780123969835.

2. Jaedig, F.; Schefer, L.; Diener, M.; Adamcik, J.; Sa, A. Primary, Secondary, Tertiary and Quaternary Structure Levels in Linear Polysaccharides: From Random Coil, to Single Helix to Supramolecular Assembly. Biomacromolecules 2019, 20, 1731-1739. [CrossRef]

3. Cho, E.; Jung, S. Supramolecular Complexation of Carbohydrates for the Bioavailability Enhancement of Poorly Soluble Drugs. Molecules 2015, 20, 19620-19646. [CrossRef]

4. Akiyoshi, K.; Sunamoto, J. Supramolecular assembly of hydrophobized polysaccharides. Supramol. Sci. 1996, 3, 157-163. [CrossRef]

5. Scott, R.A.; Panitch, A. Glycosaminoglycans in biomedicine. Wiley Interdiscip. Rev. Nanomed. Nanobiotechnol. $2013,5,388-398$. [CrossRef] [PubMed]

6. Necas, J.; Bartosikova, L.; Brauner, P.; Kolar, J. Hyaluronic acid (hyaluronan): A review. Vet. Med. 2008, 53, 397-411. [CrossRef]

7. Dicker, K.T.; Gurski, L.A.; Pradhan-Bhatt, S.; Witt, R.L.; Farach-Carson, M.C.; Jia, X. Hyaluronan: A simple polysaccharide with diverse biological functions. Acta Biomater. 2014, 10, 1558-1570. [CrossRef]

8. Cowman, M.K.; Schmidt, T.A.; Raghavan, P.; Stecco, A. Viscoelastic Properties of Hyaluronan in Physiological Conditions. F1000Research 2015, 4, 622. [CrossRef]

9. Swann, D.A.; Radin, E.L.; Nazimiec, M.; Weisser, P.A.; Curran, N.; Lewinnek, G. Role of hyaluronic acid in joint lubrication. Ann. Rheum. Dis. 1974, 33, 318-326. [CrossRef]

10. Radin, E.L.; Paul, I.L.; Swann, D.A.; Schottstaedt, E.S. Lubrication of synovial membrane. Ann. Rheum. Dis. 1971, 30, 322-325. [CrossRef] [PubMed]

11. Salwowska, N.; Bebenek, K.A.; Zadło, D.A.; Wcisło-Dziadecka, D.L. Physiochemical properties and application of hyaluronic acid: A systematic review. J. Cosmet. Dermatol. 2016, 15, 520-526. [CrossRef]

12. Tiwari, S.; Bahadur, P. Modified hyaluronic acid based materials for biomedical applications. Int. J. Biol. Macromol. 2019, 121, 556-571. [CrossRef]

13. Lapčík, L.; Lapčík, L.; De Smedt, S.; Demeester, J.; Chabreček, P. Hyaluronan: Preparation, structure, properties, and applications. Chem. Rev. 1998, 98. [CrossRef] 
14. Volpi, N.; Schiller, J.; Stern, R. Role, Metabolism, Chemical Modifications and Applications of Hyaluronan. Curr. Med. Chem. 2009, 16, 1718-1745. [CrossRef]

15. Segura, T.; Anderson, B.C.; Chung, P.H.; Webber, R.E.; Shull, K.R.; Shea, L.D. Crosslinked hyaluronic acid hydrogels: A strategy to functionalize and pattern. Biomaterials 2005, 26, 359-371. [CrossRef]

16. Yalpani, M.; Hall, L.D. Some chemical and analytical aspects of polysaccharide modifications. III. Formation of branched-chain, soluble chitosan derivatives. Macromolecules 1984, 17, 272-281. [CrossRef]

17. D'Amelio, N.; Esteban, C.; Coslovi, A.; Feruglio, L.; Uggeri, F.; Villegas, M.; Benegas, J.; Paoletti, S.; Donati, I. Insight into the Molecular Properties of Chitlac, a Chitosan Derivative for Tissue Engineering. J. Phys. Chem. B 2013, 117, 13578-13587. [CrossRef]

18. Laffleur, F.; Netsomboon, K.; Erman, L.; Partenhauser, A. Evaluation of modified hyaluronic acid in terms of rheology, enzymatic degradation and mucoadhesion. Int. J. Biol. Macromol. 2018, 123, 1204-1210. [CrossRef] [PubMed]

19. Saitoh, H.; Takagaki, K.; Majimas, M.; Nakamura, T.; Matsuki, A.; Kasai, M.; Narita, H.; Endo, M. Enzymic Reconstruction of Glycosaminoglycan Oligosaccharide Chains Using the Transglycosylation Reaction of Bovine Testicular Hyaluronidase. J. Biol. Chem. 1995, 270, 3741-3747. [CrossRef] [PubMed]

20. Ren, D.; Yi, H.; Ma, X. The enzymatic degradation and swelling properties of chitosan matrices with different degrees of $\mathrm{N}$ -acetylation. Carbohydr. Res. 2005, 340, 2403-2410. [CrossRef] [PubMed]

21. Deb, S.; Abueva, C.; Kim, B.; Taek, B. Chitosan-hyaluronic acid polyelectrolyte complex scaffold crosslinked with genipin for immobilization and controlled release of BMP-2. Carbohydr. Polym. 2015, 115, 160-169. [CrossRef]

22. Tsao, C.T.; Chang, C.H.; Lin, Y.Y.; Wu, M.F.; Wang, J.L.; Young, T.H.; Han, J.L.; Hsieh, K.H. Evaluation of chitosan/ $\gamma$-poly(glutamic acid) polyelectrolyte complex for wound dressing materials. Carbohydr. Polym. 2011, 84, 812-819. [CrossRef]

23. Lehmann, P.; Symitz, C.; Brezesinski, G.; Kra $\beta$, H.; Kurth, D.G. Langmuir and Langmuir-Blodgett Films of Metallosupramolecular Polyelectrolyte-Amphiphile Complexes. Langmuir 2005, 21, 5901-5906. [CrossRef]

24. Ji, D.; Kuo, T.; Wu, H.; Yang, J.; Lee, S. A novel injectable chitosan / polyglutamate polyelectrolyte complex hydrogel with hydroxyapatite for soft-tissue augmentation. Carbohydr. Polym. 2012, 89, 1123-1130. [CrossRef] [PubMed]

25. Denuzière, A.; Ferrier, D.; Domard, A. Interactions between chitosan and glycosaminoglycans (chondroitin sulfate and hyaluronic acid): Physicochemical and biological studies. Ann. Pharm. Françaises 2000, 58, 47-53.

26. Coueta, F.; Rajana, N. Diego Mantovani Macromolecular Biomaterials for Scaffold-Based Vascular Tissue Engineering. Macromol. Biosci. 2007, 7, 701-718. [CrossRef]

27. Florczyk, S.J.; Wang, K.; Jana, S.; Wood, D.L.; Sytsma, S.K.; Sham, J.G.; Kievit, F.M.; Zhang, M. Biomaterials Porous chitosanhyaluronic acid scaffolds as a mimic of glioblastoma microenvironment ECM. Biomaterials 2013, 34, 10143-10150. [CrossRef]

28. Muzzarelli, C.; Stanic, V.; Gobbi, L.; Tosi, G.; Muzzarelli, R.A.A. Spray-drying of solutions containing chitosan together with polyuronans and characterisation of the microspheres. Carbohydr. Polym. 2004, 57, 73-82. [CrossRef]

29. Kayitmazer, A.B.; Koksal, A.F.; Kilic Iyilik, E. Complex coacervation of hyaluronic acid and chitosan: Effects of pH, ionic strength, charge density, chain length and the charge ratio. Soft Matter 2015, 11, 8605-8612. [CrossRef]

30. Furlani, F.; Donati, I.; Marsich, E.; Sacco, P. Characterization of Chitosan/Hyaluronan Complex Coacervates Assembled by Varying Polymers Weight Ratio and Chitosan Physical-Chemical Composition. Colloids Interfaces 2020, 4, 12. [CrossRef]

31. Lalevée, G.; David, L.; Montembault, A.; Blanchard, K.; Meadows, J.; Malaise, S.; Crépet, A.; Grillo, I.; Morfin, I.; Delair, T.; et al. Highly stretchable hydrogels from complex coacervation of natural polyelectrolytes. Soft Matter 2017, 13, 6594-6605. [CrossRef]

32. Kononova, S.V.; Kruchinina, E.V.; Petrova, V.A.; Baklagina, Y.G.; Klechkovskaya, V.V.; Orekhov, A.S.; Vlasova, E.N.; Popova, E.N.; Gubanova, G.N.; Skorik, Y.A. Pervaporation membranes of a simplex type with polyelectrolyte layers of chitosan and sodium hyaluronate. Carbohydr. Polym. 2019, 209, 10-19. [CrossRef]

33. Salamanna, F.; Giavaresi, G.; Parrilli, A.; Martini, L.; Nicoli Aldini, N.; Abatangelo, G.; Frizziero, A.; Fini, M. Effects of intra-articular hyaluronic acid associated to Chitlac (arty-duo ${ }^{\circledR}$ ) in a rat knee osteoarthritis model. J. Orthop. Res. 2019, 37, 867-876. [CrossRef]

34. Tarricone, E.; Mattiuzzo, E.; Belluzzi, E.; Elia, R.; Benetti, A.; Venerando, R.; Vindigni, V.; Ruggieri, P.; Brun, P. Anti-Inflammatory Performance of Lactose-Modified Osteoarthritis Model. Cells 2020, 9, 1328. [CrossRef]

35. Bertini, S.; Bisio, A.; Torri, G.; Bensi, D. Molecular Weight Determination of Heparin and Dermatan Sulfate by Size Exclusion Chromatography with a Triple Detector Array. Biomacromolecules 2005, 6, 168-173. [CrossRef]

36. Alekseeva, A.; Raman, R.; Eisele, G.; Clark, T.; Fisher, A.; Larry, S.; Jiang, X.; Torri, G.; Sasisekharan, R.; Bertini, S.; et al. In-depth structural characterization of pentosan polysulfate sodium complex drug using orthogonal analytical tools. Carbohydr. Polym. 2020, 234, 115913. [CrossRef] [PubMed]

37. Harding, A.; Theisen, C.; Deacon, M.P.; Harding, S.E. Refractive Increment Data-Book, 1st ed.; Nottingham University Press: Nottingham, UK, 1999; ISBN 1897676298.

38. Fernandez-Megia, E.; Novoa-Carballal, R.; Quinoà, E.; Riguera, R. Optimal routine conditions for the determination of the degree of acetylation of chitosan by 1 H-NMR. Carbohydr. Polym. 2005, 61, 155-161. [CrossRef]

39. Donati, I.; Stredanska, S.; Silvestrini, G.; Vetere, A.; Marcon, P.; Marsich, E. The aggregation of pig articular chondrocyte and synthesis of extracellular matrix by a lactose-modified chitosan. Biomaterials 2005, 26, 987-998. [CrossRef]

40. Johnson, C.S., Jr. Diffusion ordered nuclear magnetic resonance spectroscopy: Principles and applications. Prog. Nucl. Magn. Reson. Spectrosc. 1999, 34, 203-256. [CrossRef] 
41. Pinheiro, J.P.; Domingos, R.; Lopez, R.; Brayner, R.; Fiévet, F.; Wilkinson, K. Determination of diffusion coefficients of nanoparticles and humic substances using scanning stripping chronopotentiometry (SSCP). Colloids Surf. A Physiochem. Eng. Asp. 2007, 295, 200-208. [CrossRef]

42. Viel, S.; Mannina, L.; Segre, A. Detection of a $\pi-\pi$ complex by diffusion-ordered spectroscopy (DOSY). Tetrahedron Lett. 2002, 43, 2515-2519. [CrossRef]

43. Li, W.; Kagan, G.; Hopson, R.; Williard, P.G. Measurement of Solution Viscosity via Diffusion-Ordered NMR Spectroscopy (DOSY). J. Chem. Educ. 2011, 88, 1331-1335. [CrossRef]

44. Price, K.E.; Lucas, L.H.; Larive, C.K. Analytical applications of NMR diffusion measurements. Anal. Bioanal. Chem. 2004, 378, 1405-1407. [CrossRef] [PubMed]

45. Cobas, J.C.; Groves, P.; Martìn-Pastor, M.; De Capua, A. New Applications, Processing Methods and Pulse Sequences Using Diffusion NMR. Curr. Anal. Chem. 2005, 1, 289-305. [CrossRef]

46. Peuravuori, J. NMR Spectroscopy Study of Freshwater Humic Material in Light of Supramolecular Assembly. Environ. Sci. Technol. 2005, 39, 5541-5549. [CrossRef] [PubMed]

47. Jerschow, A.; Müller, N. Diffusion-separated nuclear magnetic resonance spectroscopy of polymer mixtures. Macromolecules 1998, 31, 6573-6578. [CrossRef]

48. Ambrosio, L.; Borzacchiello, A.; Netti, P.A.; Nicolais, L. Rheological study on hyaluronic acid and its derivative solutions. J. Macromol. Sci. Part A Pure Appl. Chem. 2007, 36, 991-1000. [CrossRef]

49. Yang, T.; Chou, C.; Li, C. Preparation, water solubility and rheological property of the $\mathrm{N}$-alkylated mono or disaccharide chitosan derivatives. Food Res. Int. 2002, 35, 707-713. [CrossRef]

50. Jiang, J.; Oberdörster, G.; Biswas, P. Characterization of size, surface charge, and agglomeration state of nanoparticle dispersions for toxicological studies. J. Nanoparticle Res. 2009, 11, 77-89. [CrossRef]

51. Hunter, R.J. Interaction between Colloidal Particles. In Zeta Potential in Colloid Science; Rowell, R.H., Ottewill, R.L., Eds.; Academic Press: Sydney, Australia, 1981; pp. 363-369.

52. Freitas, C.; Müller, R.H. Effect of light and temperature on zeta potential and physical stability in solid lipid nanoparticle (SLN ${ }^{\mathrm{TM}}$ ) dispersions. Int. J. Pharm. 1998, 168, 221-229. [CrossRef]

53. Shah, R.; Eldridge, D.; Palombo, E.; Harding, I. Optimisation and stability assessment of solid lipid nanoparticles using particle size and zeta potential. J. Phys. Sci. 2014, 25, 59-75.

54. Bertini, S.; Fareed, J.; Madaschi, L.; Risi, G.; Torri, G.; Naggi, A. Characterization of PF4-Heparin Complexes by Photon Correlation Spectroscopy and Zeta Potential. Clin. Appl. Thromb. 2017, 23, 725-734. [CrossRef] [PubMed]

55. Deville, S. Ice-templating, freeze casting: Beyond materials processing. J. Mater. Res. 2013, 28, 2202-2219. [CrossRef]

56. Cooney, M.J.; Lau, C.; Windmeisser, M.; Liaw, B.Y.; Klotzbach, T.; Minteer, S.D. Design of chitosan gel pore structure: Towards enzyme catalyzed flow-through electrodes. J. Mater. Chem. 2008, 18, 667-674. [CrossRef]

57. Orsolini, P.; Antonini, C.; Stojanovic, A.; Malfait, W.J.; Caseri, W.R.; Zimmermann, T. Superhydrophobicity of nanofibrillated cellulose materials through polysiloxane nanofilaments. Cellulose 2018, 25, 1127-1146. [CrossRef]

58. Antonini, C.; Wu, T.; Zimmermann, T.; Kherbeche, A.; Thoraval, M.-J.; Nystrom, G.; Geiger, T. Ultra-Porous Nanocellulose Foams: A Facile and Scalable Fabrication Approach. Nanomaterials 2019, 9, 1142. [CrossRef]

59. Pawelec, K.M.; Husmann, A.; Best, S.M.; Cameron, R.E. Ice-templated structures for biomedical tissue repair: From physics to final scaffolds. Appl. Phys. Rev. 2014, 1, 021301. [CrossRef]

60. Zhang, W.; Jin, X.; Li, H.; Zhang, R.; Wu, C. Injectable and body temperature sensitive hydrogels based on chitosan and hyaluronic acid for $\mathrm{pH}$ sensitive drug release. Carbohydr. Polym. 2018, 186, 82-90. [CrossRef] [PubMed] 